\title{
The role of insulin glulisine to improve glycemic control in children with diabetes mellitus
}

This article was published in the following Dove Press journal:

Diabetes, Metabolic Syndrome and Obesity:Targets and Therapy

25 November 2010

Number of times this article has been viewed

\author{
Anna Lih \\ Emily Hibbert \\ Tang Wong \\ Christian M Girgis \\ Nidhi Garg \\ John N Carter \\ Department of Endocrinology \\ and Metabolism, Concord Hospital, \\ NSW, Australia; University of Sydney, \\ Camperdown, NSW, Australia
}

\begin{abstract}
Glulisine (Apidra ${ }^{\circledR}$ ) is a rapid-acting human insulin analog approved for use in children with diabetes mellitus $\geq 4$ years of age. Management of children with type 1 diabetes has seen a shift in favor of mimicking normal physiological insulin responses with multiple daily injections or continuous subcutaneous insulin infusions (CSII). Few studies have compared the rapid-acting insulin analogs in this population but limited data indicate that glulisine is as effective as lispro when used in a basal-bolus regimen. This review appraises the current available studies and reviews on insulin glulisine in children. An extensive keyword search of 'insulin glulisine', 'insulin analogs', and 'Apidra' in the pediatric population was performed. These studies have suggested that glulisine is safe, well tolerated, and is an effective option in the diabetes armamentarium. Further studies are needed to determine its safety for use in CSII pumps in the pediatric population.
\end{abstract}

Keywords: glulisine, pediatrics, type 1 diabetes mellitus

\section{Introduction}

Type 1 diabetes mellitus is one of the most common chronic diseases in children in the developed world. The incidence in children is growing at 3\% to $5 \%$ per year ${ }^{1}$ and the risk of hypoglycemia has always been a limiting factor in attempts to achieve near-normoglycemia. In recent years, particularly because of improved insulins and insulin delivery devices, it has been possible to lower blood glucose levels more easily with a reduced risk of hypoglycemia, thus decreasing the chances of microvascular, macrovascular, and neuropathic damage (ie, diabetes complications) in the future. The Diabetes Control and Complications Trial (DCCT) ${ }^{2}$ and its follow-up study, Epidemiology of Diabetes Interventions and Complications (EDIC), ${ }^{3}$ highlighted that a reduction in glycosylated hemoglobin $\left(\mathrm{HbA}_{1 c}\right)$, even when it remains above the recommended target goal, has a beneficial impact on long-term prognosis, the now recognized 'metabolic memory effect', important in minimizing microvascular and macrovascular complications. ${ }^{2-4}$

Metabolic memory is based on the concept that initial poor glycemic control during the diabetes disease course is associated with an increased risk of diabetes complications, despite optimal glycemic control later in the disease course (and vice versa). This emphasizes the desirability of attaining and maintaining excellent glycemic control from the time of diagnosis. However, in children and adolescents with type 1 diabetes, this may be difficult to obtain as a result of the need to balance multiple daily insulin injections with variations in dietary and exercise patterns.

\footnotetext{
Correspondence: John Carter

Department of Endocrinology and

Metabolism, Level 6, Concord Hospital

Medical Center, Concord Hospital,

Concord, NSW, Australia

Tel +6 I 029477370 I

Fax +6I 0294822036

Email jcarter@bigpond.net.au
}

submit your manuscript $\mid$ www.dovepress.com

Dovepress

DOI: 10.2147/DMSOTT.S5116
Diabetes, Metabolic Syndrome and Obesity:Targets and Therapy 2010:3 403-4I2

(C) 2010 Lih et al, publisher and licensee Dove Medical Press Ltd. This is an Open Access article which permits unrestricted noncommercial use, provided the original work is properly cited. 
The approach to diabetes management is complex, and hypoglycemia arising from attempts to achieve normoglycemia (or near-normoglycemia) is understandably feared by children, parents, and clinicians. Despite this, in recent years, there has been a shift in the approach to managing children with newly diagnosed type 1 diabetes, in order to optimize their glycemic control. This has been aided by the availability and accepted use of insulin analogs, insulin pens, and continuous subcutaneous insulin infusions (CSII) pumps.

Insulin analogs were first available for clinical use in 1996, a major advantage being reduced hypoglycemic episodes compared with regular human insulin (RHI; Figure 1). ${ }^{5,6}$ In adults, changing treatment from RHI to insulin analogs generally results in a reduction of $\mathrm{HbA}_{1 \mathrm{c}}$ levels, but a similar change has not been documented in children. Glulisine is one of the newest insulin analogs and is approved for use in children $\geq 4$ years of age (and aged $\geq 6$ years in Europe). ${ }^{7,8}$

An extensive review of the literature utilizing PubMed, EMBASE, Cochrane Collaboration, and Ovid Medline did not reveal clinical trials favoring superiority of glulisine above other insulin analogs. In this review, clinical trials that included 'glulisine' as a key word in the pediatric population were included (open and blinded, randomized, nonrandomized, crossover designs), regardless of dose or schedule. The participants of these studies were aged 4 to 17 years of age of either sex. All participants had confirmatory type 1 diabetes. The main outcome data in the efficacy studies were changes in $\mathrm{HbA}_{1 \mathrm{c}}$ at study completion. To date, efficacy data on type 2 diabetes in the pediatric population have not been studied, but several trials have been performed in adults. ${ }^{9-11}$

Additional searching was made by cross referencing original articles and reviews. Abstracts were screened from major meetings and the abstract included in this review was sourced from Diabetologica. Enquiries were made to sanofi-aventis on future research, there are two ongoing Phase IV clinical trials currently in progress, the results of which are yet to be published. These trials have not yet completed recruitment. ${ }^{12}$

This review will describe the pharmacokinetic and pharmacodynamic studies, available in children. The efficacy trials will focus on comparison of glulisine with insulin lispro. The safety concerns and quality of life issues will be discussed based on the available trials in children.

\section{Glulisine}

\section{Structure}

Glulisine (Apidra ${ }^{\circledR}$; sanofi-aventis, Paris, France) is a rapidacting recombinant insulin analog which differs from RHI by the substitution of lysine for asparagine at position B3 and glutamic acid for lysine at position B29. ${ }^{13}$

The chemical name of insulin glulisine is 3B-Lys-29BGlu-human insulin. ${ }^{14}$

Glulisine is the newest addition to the class of rapid-acting recombinant insulin analogs. Lispro is created by substituting proline for lysine at position B28 and lysine for proline at position B29, effectively reversing the amino acids sequence at positions 28 and 29 of the insulin beta-chain (Figure 3). Aspart is homologous to RHI except for the substitution of proline for aspartic acid at B28 (Figure 4).

\section{Monomers, dimmers, and hexamers}

In solution, insulin molecules exist in equilibrium between monomers, dimers, tetramers, hexamers, and higher-order aggregates. Human insulin is best absorbed in its monomeric form but, at physiologic $\mathrm{pH}$, normal insulin molecules tend to associate into dimers and subsequently hexamers in the

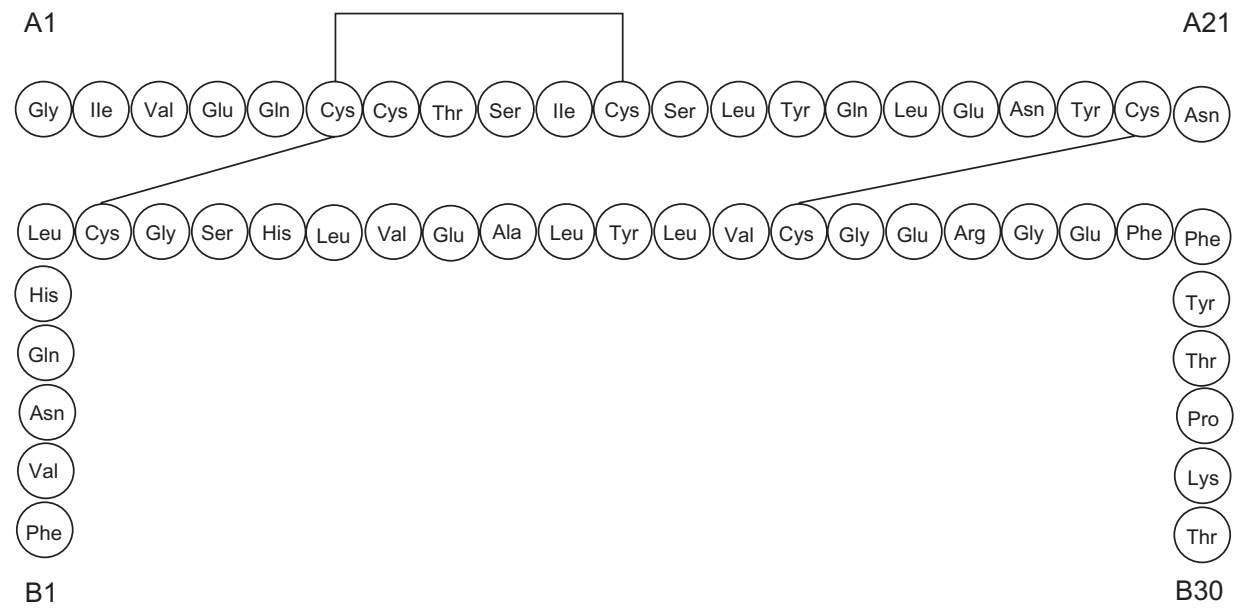

Figure I Regular human insulin. 


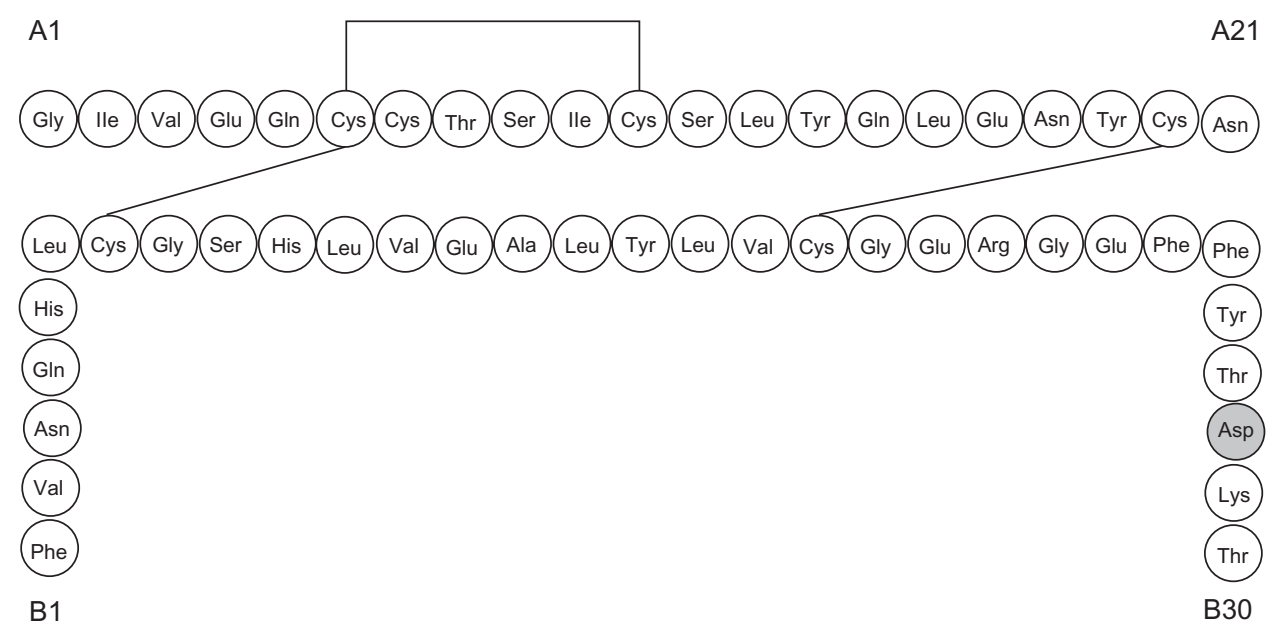

Figure 2 Aspart insulin.

presence of zinc. Consequently, the absorption of RHI is limited by the degree and strength of self association of insulin molecules. ${ }^{15}$

The amino acid substitutions of glulisine and other rapidacting insulin analogs promote monomer stability, allowing for rapid dissociation and absorption after subcutaneous injection. In addition, the isolectric point (pI) is lowered to 5.1 , enhancing solubility at physiological $\mathrm{pH} .{ }^{16}$

The dimer and hexameric forms of human insulin confer conformational stability and are less likely to denature in storage. ${ }^{17} \mathrm{In}$ aspart and lispro, zinc is added in order to stabilize the molecules in hexamers to achieve a practical shelf-life. ${ }^{18,19}$

Unlike the other rapid-acting insulin analogs, the oligomeric molecules of glulisine are stable without the addition of zinc, presumably because of the unaltered proline at position $\mathrm{B} 28$ thus allowing dimerization..$^{20}$ Polysorbate 20 , a surfactant, is added to the product composition to prevent the irreversible formation of aggregates (fibrils) from monomers, further enhancing physical stability. ${ }^{17}$

\section{Mechanism of action}

Insulin and its analogs lower serum glucose levels by facilitating glucose uptake in skeletal muscle and fat, and by inhibiting gluconeogenesis, glycogenolysis, lipolysis, and proteolysis through its effect on the insulin receptor. Compared with RHI, there are no differences in association, dissociation, or receptor binding affinity. ${ }^{21}$

\section{Pharmacokinetics and pharmacodynamics}

There have been limited studies in children evaluating pharmacokinetics and pharmacodynamics of glulisine. A doubleblind, randomized, crossover study of 20 pediatric patients incorporated a single-dose $(0.15 \mathrm{U} / \mathrm{kg})$ of either glulisine

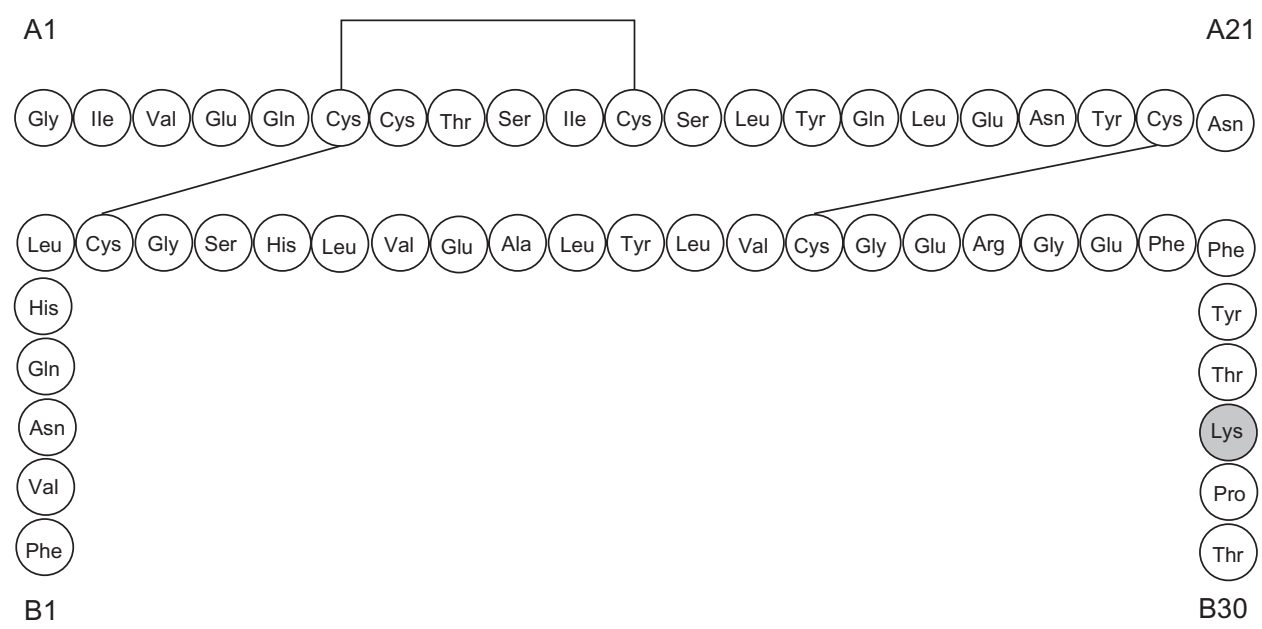

Figure 3 Lispro insulin. 


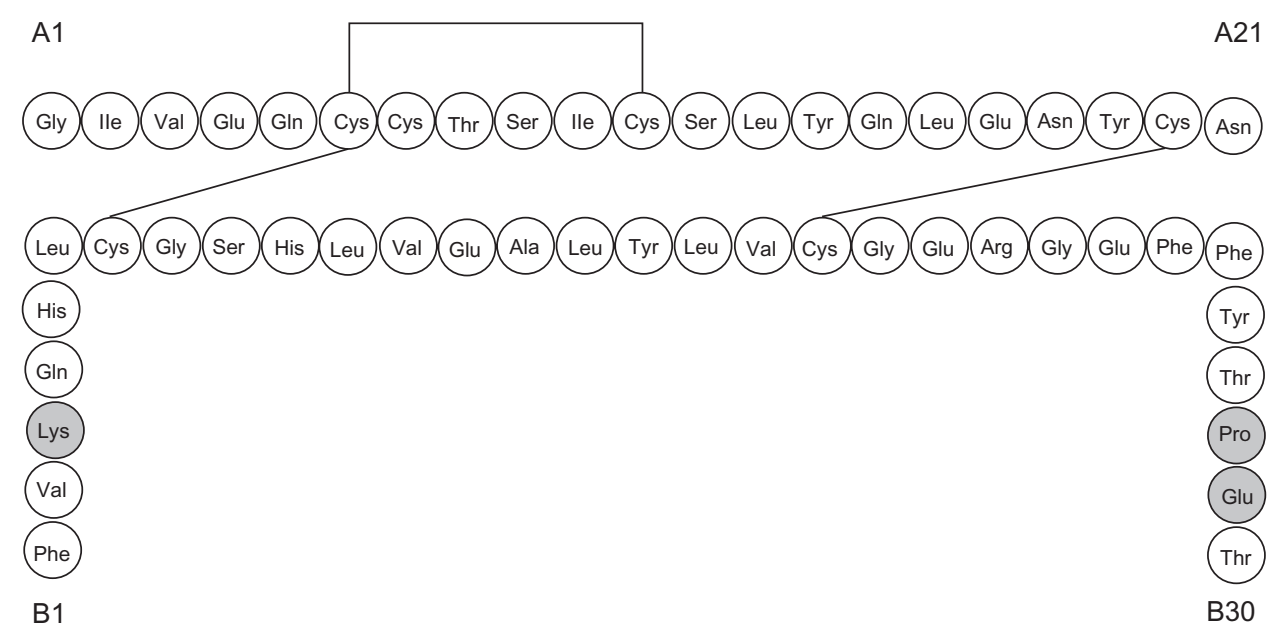

Figure 4 Glulisine insulin.

or RHI administered 2 minutes before a weight-adjusted standardized liquid meal. Patients were stratified into two groups of 10 patients each: children (aged 5 to 11 years) and adolescents (aged 12 to 17 years). ${ }^{22}$ Comparable to adults with type 1 diabetes, glulisine in children and adolescents afforded a greater early insulin exposure as assessed by (INS-AUC ${ }_{0-1 \mathrm{~h}}$ ) (insulin concentration [area under curve]) and INS-AUC ${ }_{0-2 h}$, while overall concentrations of insulin as assessed by INS-AUC ${ }_{0-6 \mathrm{~h}}$ were comparable. Glulisine reached a higher maximum concentration $\left(\mathrm{C}_{\text {max }} 58 \mu \mathrm{IU} / \mathrm{L}\right.$ vs $33 \mu \mathrm{IU} / \mathrm{L}$; $P<0.05)$ compared with RHI and achieved this in shorter period of time ( $\mathrm{t}_{\max } 54$ minutes vs 66 minutes) (see Table 1 ). The median residence time was shorter at 88 minutes compared with 137 minutes for RHI $(P<0.05)$.

Pharmacokinetic profiles for glulisine given to children and adolescents were almost equivalent, as demonstrated by point estimates close to $100 \%$. In contrast, adolescents administered RHI demonstrated a $62 \%$ higher early exposure to insulin ( $\mathrm{INS}-\mathrm{AUC}_{0-2 \mathrm{~h}}$ ), 64\% higher overall concentrations of insulin (INS-AUC ${ }_{0-6 \mathrm{~h}}$ ), and a 76\% higher insulin $\mathrm{C}_{\max }$ compared with children (see Table 2).

Total glucose exposure (BG-AUC), maximum blood glucose concentration $\left(\mathrm{BG}_{\max }\right)$, and maximum glucose excursion from baseline $\left(\Delta B G_{\max }\right)$ were also significantly lower in pediatric patients administered glulisine compared to RHI $(P<0.05)$. The trend persisted when children and adolescents were analyzed separately (see Table 3 ).

There are currently no pharmacokinetic studies comparing glulisine with lispro or aspart.

\section{Efficacy}

An Ovid Medline search of the published literature found a limited number of articles on the use of glulisine among pediatric patients. There was one published pharmacokinetic study, ${ }^{22}$ three review articles, ${ }^{23,24}$ and a recent abstract ${ }^{25}$ detailing the safety and efficacy of lispro versus glulisine. Although the data are limited, the literature is in favor of the general efficacy of glulisine as a rapid-acting analog in

Table I Pharmacokinetics of glulisine (GLU) versus regular human insulin (RHI)

\begin{tabular}{|c|c|c|c|}
\hline & GLU (geometric mean) & RHI (geometric mean) & $\begin{array}{l}\text { GLU/RHI point } \\
\text { estimate }(95 \% \mathrm{Cl})\end{array}$ \\
\hline $\mathrm{INS} \mathrm{AUC}_{0-\mathrm{Ih}}\left(\mu \mathrm{IU} \cdot \mathrm{min}^{-1} \cdot \mathrm{mL}^{-1}\right)$ & 2287 & 1246 & $176 \%(127,244)$ \\
\hline INS-AUC $_{0-2 h}\left(\mu \mathrm{IU} \cdot \mathrm{min}^{-1} \cdot \mathrm{mL}^{-1}\right)$ & 5232 & 2994 & $169 \%(127,224)$ \\
\hline INS-AUC $_{0-4 h}\left(\mu \mathrm{IU} \cdot \mathrm{min}^{-1} \cdot \mathrm{mL}^{-1}\right)$ & 7624 & 5703 & $130 \%(99,170)$ \\
\hline INS-AUC $_{0-6 \mathrm{~h}}\left(\mu \mathrm{IU} \cdot \mathrm{min}^{-1} \cdot \mathrm{mL}^{-1}\right)$ & 8361 & 7052 & $116 \%(90,150)$ \\
\hline$C_{\max }\left(\mu \mathrm{IU} \cdot \mathrm{mL}^{-1}\right)$ & 58 & 33 & $171 \%(127,229)$ \\
\hline $\mathrm{t}_{\max }(\min )$ & $54^{\mathrm{a}}$ & $66^{\dagger}$ & $-8 \min (-24,7)$ \\
\hline MRT (min) & 88 & 137 & $64 \%(59,70)$ \\
\hline
\end{tabular}

Note: a Median. Copyright $\odot$ 2005, American Diabetes Association. Adapted with permission from Danne T, Becker RH, Heise T, Bittner C, Frick AD, Rave K. Pharmacokinetics, prandial glucose control, and safety of insulin glulisine in children and adolescents with type I diabetes. Diabetes Care. 2005;28(9):2I00-2I05.

Abbreviations: $\mathrm{Cl}$, confidence limits; INS-AUC $\left(\mu \mathrm{IU} \cdot \mathrm{min}^{-1} \cdot \mathrm{mL}^{-1}\right)$, insulin concentration (area under curve); $\mathrm{C}_{\max }\left(\mu \mathrm{IU} \cdot \mathrm{mL}^{-1}\right)$, maximum insulin concentration; $\mathrm{t}_{\max }($ min), time to $C_{\max } ;$ MRT ( $\left.\mathrm{min}\right)$, median residence time. 
Table 2 Pharmacokinetics of glulisine (GLU) and regular human insulin (RHI) in children versus adolescents

\begin{tabular}{|c|c|c|c|c|c|c|}
\hline & $\begin{array}{l}\text { Children } \\
\text { GLU } \\
\text { (geometric mean) }\end{array}$ & $\begin{array}{l}\text { Children } \\
\text { RHI } \\
\text { (geometric mean) }\end{array}$ & $\begin{array}{l}\text { Adolescents } \\
\text { GLU } \\
\text { (geometric mean) }\end{array}$ & $\begin{array}{l}\text { Adolescents } \\
\text { RHI } \\
\text { (geometric mean) }\end{array}$ & $\begin{array}{l}\text { GLU } \\
\text { point estimate } \\
(95 \% \mathrm{Cl})\end{array}$ & $\begin{array}{l}\text { RHI } \\
\text { point estimate } \\
(95 \% \mathrm{CI})\end{array}$ \\
\hline $\begin{array}{l}\text { INS-AUC }_{0-1 \mathrm{~h}} \\
\left(\mu \mathrm{IU} \cdot \mathrm{min}^{-1} \cdot \mathrm{mL}^{-1}\right)\end{array}$ & 2170 & 1023 & 2410 & 1552 & $\begin{array}{l}111 \% \\
(70,175)\end{array}$ & $\begin{array}{l}152 \% \\
(89,258)\end{array}$ \\
\hline $\begin{array}{l}\text { INS-AUC }_{0-2 h} \\
\left(\mu \mathrm{IU} \cdot \mathrm{min}^{-1} \cdot \mathrm{mL}^{-1}\right)\end{array}$ & 4948 & 2383 & 5534 & 3860 & $\begin{array}{l}112 \% \\
(72,174)\end{array}$ & $162 \%(105,250)$ \\
\hline $\begin{array}{l}\text { INS-AUC }_{0-4 h} \\
\left(\mu I U \cdot \mathrm{min}^{-1} \cdot \mathrm{mL}^{-1}\right)\end{array}$ & 7193 & 4530 & 8081 & 7367 & $\begin{array}{l}112 \% \\
(72,175)\end{array}$ & $163 \%(111,238)$ \\
\hline $\begin{array}{l}\text { INS-AUC }_{0-6 h} \\
\left(\mu \mathrm{IU} \cdot \mathrm{min}^{-1} \cdot \mathrm{mL}^{-1}\right)\end{array}$ & 7934 & 5581 & 8811 & 9145 & $\begin{array}{l}111 \% \\
(73,169)\end{array}$ & $164 \%(114,236)$ \\
\hline$C_{\max }\left(\mu \mathrm{IU} \cdot \mathrm{mL}^{-1}\right)$ & 55 & 25 & 61 & 44 & $\begin{array}{l}112 \% \\
(73,172)\end{array}$ & $177 \%(|1| 2,28 I)$ \\
\hline $\mathrm{t}_{\max }(\min )$ & $55^{\mathrm{a}}$ & $59^{a}$ & $52^{\dagger}$ & $76^{\mathrm{a}}$ & $\begin{array}{l}-2 \min ^{\mathrm{b}} \\
(-9,1 \mathrm{II})\end{array}$ & $\begin{array}{l}9 \min ^{\mathrm{b}} \\
(-24,49)\end{array}$ \\
\hline MRT (min) & 87 & 132 & 90 & 144 & $\begin{array}{l}103 \% \\
(88,121)\end{array}$ & $\begin{array}{l}110 \% \\
(92,130)\end{array}$ \\
\hline
\end{tabular}

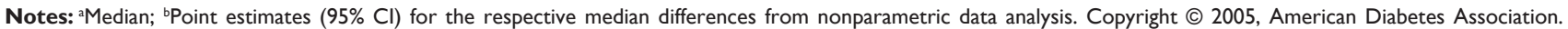
Adapted with permission from Danne T, Becker RH, Heise T, Bittner C, Frick AD, Rave K. Pharmacokinetics, prandial glucose control, and safety of insulin glulisine in children and adolescents with type I diabetes. Diabetes Care. 2005;28(9):2 I00-2 I 05.

Abbreviations: $\mathrm{Cl}$, confidence limits; INS AUC $\left(\mu \mathrm{IU} \cdot \mathrm{min}^{-1} \cdot \mathrm{mL}^{-1}\right)$, insulin concentration (area under curve); $\mathrm{C}_{\max }\left(\mu l \mathrm{U} \cdot \mathrm{mL}^{-1}\right)$, maximum insulin concentration; $\mathrm{t}_{\max }(\mathrm{min})$, time to $C_{\max } ; M R T(\min )$, median residence time.

pediatric patients. There are insufficient data to support its efficacy and safety via CSII. ${ }^{26,27}$

\section{Glulisine versus lispro}

A 26-week, multicenter, centrally randomized noninferiority trial compared the efficacy of glulisine with lispro in 572 children (aged 4 to 17 years) with type 1 diabetes treated with basal insulin (either glargine once daily or NPH twice daily). ${ }^{25}$ Most patients had 3 to 4 bolus injections (58\% of those on glulisine, $60.5 \%$ of those on lispro) and blood glucose control remained stable throughout the study period. Baseline-to-endpoint $\mathrm{HbA}_{1 \mathrm{c}}$ changes were similar in both groups (glulisine lispro $-0.06 \%, 95 \%$ confidence interval -0.24 to 0.12 ; prespecified noninferiority margin $0.4 \%)$. However, the percentage of patients achieving
American Diabetes Association (ADA) age-specific $\mathrm{HbA}_{1 \mathrm{c}}$ targets at endpoint was significantly higher with glulisine (38.4\%) than with lispro $(32 \%)(P=0.0386)$. This difference was particularly pronounced in adolescents (13 to 17 years), $31.1 \%$ of glulisine-treated subjects versus $21.1 \%$ of lispro-treated subjects achieving the age-specific $\mathrm{HbA}_{1 \mathrm{c}}$ target of $<7.5 \%$ at endpoint $(P=0.0251)$.

Based on these findings, Philotheou et $\mathrm{al}^{25}$ concluded that glulisine is noninferior to lispro in the long-term reduction of $\mathrm{HbA}_{1 \mathrm{c}}$ in pediatric patients with type I diabetes.

Several well designed trials have studied glulisine (with and without basal insulin) with comparator insulin analogs in adults. In adults with type 1 diabetes the efficacy has been investigated in three randomized, active-controlled, noninferiority studies. ${ }^{28-30}$ Two of these studies evaluated glulisine

Table 3 Postprandial glucose glulisine (GLU) versus regular human insulin (RHI)

\begin{tabular}{|c|c|c|c|}
\hline & Glulisine (Geometric mean) & RHI (Geometric mean) & $\begin{array}{l}\text { GLU/RHI } \\
\text { point estimate } \\
\text { ( } 95 \% \text { confidence limits) }\end{array}$ \\
\hline$B G-A \cup C_{0-1 h}\left(m g \cdot h^{-1} \cdot \mathrm{dL}^{-1}\right)$ & 57 & 29 & $73 \%(59,90)$ \\
\hline$B G-A \cup C_{0-2 h}\left(m g \cdot h^{-1} \cdot d^{-1}\right)$ & 179 & 263 & $68 \%(56,82)$ \\
\hline BG-AUC $_{0-4 h}\left(\mathrm{mg} \cdot \mathrm{h}^{-1} \cdot \mathrm{dL}^{-1}\right)$ & 419 & 627 & $67 \%(55,80)$ \\
\hline BG-AUC $_{0-6 \mathrm{~h}}\left(\mathrm{mg} \cdot \mathrm{h}^{-1} \cdot \mathrm{dL}^{-1}\right)$ & 641 & 801 & $80 \%(67,95)$ \\
\hline$B G_{\max }(\mathrm{mg} / \mathrm{dL})$ & 298 & 352 & $85 \%(77,93)$ \\
\hline$\Delta \mathrm{BG}_{\max }(\mathrm{mg} / \mathrm{dL})$ & 166 & 224 & $74 \%(64,86)$ \\
\hline$B G_{\min }(\mathrm{mg} / \mathrm{dL})$ & 211 & 193 & $109 \%(93,128)$ \\
\hline
\end{tabular}

Notes: Copyright (C) 2005, American Diabetes Association. Adapted with permission from Danne T, Becker RH, Heise T, Bittner C, Frick AD, Rave K. Pharmacokinetics, prandial glucose control, and safety of insulin glulisine in children and adolescents with type I diabetes. Diabetes Care. 2005;28(9):2 I00-2I05.

Abbreviations: $B G$ AUC, blood glucose (area under curve); $\triangle B_{G_{m a x}}$, maximum baseline subtracted blood glucose concentration; $B G_{\text {max }}$, maximum glucose excursion from baseline; $\mathrm{BG}_{\mathrm{min}}$, minimum blood glucose concentrations. 
with insulin lispro. ${ }^{29,30}$ The primary endpoint in these studies were changes in $\mathrm{HbA}_{1 \mathrm{c}}$ from baseline to study endpoint. The baseline characteristics of these adult type 1 diabetes participants were similar between the two groups (glulisine vs lispro). Glulisine in both studies was noninferior to lispro and the increase in basal insulin (glargine) dose in glulisine recipients was lower than in the lispro group.

\section{Glulisine versus aspart}

There were no trials comparing the efficacy of glulisine with aspart in pediatric patients.

\section{Glulisine and CSII}

Glulisine has not been approved by the Food Drug Administration for use in children or adults via CSII, but two clinical ${ }^{26,27}$ and two in vitro studies have investigated its use.

One study, performed in adult patients, was a 12-week multicenter, randomized trial that compared the efficacy and safety of glulisine versus aspart used in CSII in 59 patients with type I diabetes. ${ }^{26}$ The median catheter occlusion rate, overall rate of catheter change, and frequency of infusion site reactions were similar for both insulin forms. Each treatment group showed a slight increase in mean $\mathrm{HbA}_{1 \mathrm{c}}$ over the 12 weeks $(0.2 \%$ increase for glulisine, $0.1 \%$ increase for aspart).

The second clinical study, which included adolescents and adults, was a crossover trial looking at timing of meal-related glulisine bolus administration via CSII in 23 subjects. ${ }^{27}$ A bolus of glulisine 20 minutes prior to a meal was found to result in significantly better postprandial glucose control than glulisine administration immediately prior to the meal or 20 minutes after meal initiation.

An important property of insulin products in CSII is their ability to remain soluble and resist precipitation when exposed to various environments. Although the longest duration clinical study using CSII with glulisine did not show any increase in catheter occlusion rates compared with aspart, ${ }^{19}$ in vitro studies suggest glulisine could theoretically be more liable to precipitate. One study, utilizing reverse-phase high performance liquid chromatography to assess resistance to isoelectric precipitation of various types of insulin, ${ }^{16}$ found that the resistance was highest for aspart and lowest for glulisine, but the clinical significance of this is unclear. A second in vitro study assessed the stability of glulisine and aspart during simulated use in insulin pumps (flow rates $0.3 \mathrm{U} /$ hour and $0.9 \mathrm{U} /$ hour).$^{30}$ Although both forms of insulin initially retained high proportions of native insulin, at day 10 glulisine contained double the amount of high-molecular-weight proteins, which are less biologically potent than the native molecule and may potentially be immunogenic. Glulisine has also been shown to be more prone than aspart to form insoluble insulin fibrils, which are not biologically potent. On the basis of these studies, it is clear that further studies will be required before glulisine can be approved for use in CSII.

\section{Phase IV ongoing clinical trials}

There are two Phase IV ongoing trials with glulisine in children and adolescents with type 1 diabetes. ${ }^{12}$ Both trials are currently recruiting patients, and both are proposed to be completed in 2010. To date no data are available (see Table 4).

\section{Safety}

Studies suggest that glulisine has a similar safety profile to the other new rapid-acting insulin analogs and that it is well tolerated. $1,21,22,25,26,32,33$

\section{Hypoglycemia}

The most common adverse event with glulisine, as with all insulins is hypoglycemia. ${ }^{32}$ However, hypoglycemia does not

Table 4 Ongoing phase 4 studies of glulisine in children and adolescents

\begin{tabular}{|c|c|c|c|c|}
\hline Investigator & Year of study & Age & Inclusion criteria & Study design and aim \\
\hline Cemeroglua & $2009-2010$ & $4-11$ years & $\begin{array}{l}\text { Prepubertal (tanner stage I) } \\
\text { Type I diabetes mellitus with positive islet } \\
\text { cell antibodies or presenting at time of } \\
\text { diagnosis with positive serum or urine } \\
\text { ketones and requiring insulin since diagnosis } \\
\mathrm{HbA}_{\mathrm{Ic}} 6.9 \%-10 \%\end{array}$ & $\begin{array}{l}\text { Crossover study: } \\
\text { The effect of glulisine and aspart on breakfast } \\
\text { postprandial blood glucose levels in prepubertal } \\
\text { children with type I diabetes mellitus on multiple } \\
\text { daily insulin injection therapy }\end{array}$ \\
\hline Phillip ${ }^{b}$ & $2009-2010$ & $7-20$ years & $\begin{array}{l}\text { Type I diabetes diagnosed }<12 \text { months prior } \\
\text { to study entry } \\
\mathrm{HbA}_{\mathrm{Ic}} \geq 8.0\end{array}$ & $\begin{array}{l}\text { A randomized, crossover, open study in order to } \\
\text { compare treatment satisfaction with glargine plus } \\
\text { glulisine vs NPH insulin plus glulisine in newly } \\
\text { diagnosed children and adolescents with type I } \\
\text { diabetes }\end{array}$ \\
\hline
\end{tabular}

Notes: a Clinical trials gov identifier NCT00913497, Principal Investigator A. Cemiroglu; ${ }^{\circ}$ Clinical Trials gov identifier NCT00925977, Principal Investigator M. Phillip. 
appear to be any more frequent or severe with glulisine than with other rapid-acting insulin analogs.

Philotheou et $\mathrm{al}^{25}$ conducted a 26-week multicenter open centrally randomized, parallel group, noninferiority trial of 572 children and adolescents, aged 4 to 17 years with type 1 diabetes using glargine once daily in the evening or NPH twice daily as basal insulin and glulisine or lispro as the bolus insulin. Despite a significantly higher percentage of patients on glulisine achieving ADA age-specific $\mathrm{HbA}_{1 \mathrm{c}}$ targets at endpoint (38.4\% vs $32 \%$ in the lispro group; $P=0.0386$ ) and total and severe symptomatic hypoglycemic rates were similar between the two groups from the fourth month to the endpoint. There were 3.10 hypoglycemic events per patient per month for the glulisine group versus 2.91 for the lispro group while, for severe symptomatic hypoglycemia, there were 0.06 events per patient per month in the glulisine group and 0.07 in the lispro group.

A small crossover trial of 10 children and 10 adolescent patients with type 1 diabetes comparing RHI and glulisine found no severe hypoglycemic events. ${ }^{22}$

There are no trials of glulisine use in CSII in a purely pediatric population, but in a study in 59 adults with type 1 diabetes comparing glulisine with aspart a similar frequency of hypoglycemia was found between the two groups. ${ }^{26}$

\section{Hypersensitivity and Insulin injection site reactions}

In children no generalized hypersensitivity reactions have been reported, although there are few studies in this population.

In a pooled analysis of 1833 patients receiving glulisine versus comparator short-acting insulin in 1524 patients, both groups had a $4 \%$ incidence of potential systemic allergic reactions. ${ }^{32}$ In a 26-week study of 672 adults with type 1 diabetes. ${ }^{14}$ Dreyer et al found that systemic hypersensitivity reactions occurred in $1.8 \%$ of the glulisine group and $1.2 \%$ of the lispro group. Insulin injection site reactions occurred in $3 \%$ of patients on glulisine and $4 \%$ of those on lispro. ${ }^{14}$

When glulisine was compared with aspart in CSII in 59 adult patients with type 1 diabetes the frequency of infusionsite reactions was similar between the two groups. ${ }^{26}$

\section{Cancer risk}

There is no evidence that glulisine or any of the other rapid-acting insulin analogs cause increased mitogenesis, potentially leading to cancer, compared with RHI. There is a theoretical concern that they could increase the risk of tumor development due to altered binding characteristics to insulin and insulin-like growth factor (IGF)-1 receptors caused by the structural changes made to the native insulin molecule. However, preclinical studies suggest that structural changes in glulisine compared with RHI are not associated with any risk of tumorigenesis. ${ }^{21,33}$

Stammberger showed that steady state insulin receptor binding affinity was slightly lower for glulisine than for RHI $(\sim 0.70)$ and that glulisine has a 4- to 5-fold lower affinity for IGF-1 receptor binding than RHI. ${ }^{33}$ Glulisine and RHI showed similar insulin receptor-association kinetics and insulin receptor-mediated phosphorylation and insulin receptor substrate (IRS)-2 activation. Activation of IRS-1 was 6- to 10 -fold lower with glulisine. Stimulation of DNA synthesis was comparable for glulisine and RHI in K6 myoblasts and there was no difference in proliferative activity between the two insulins at 12 months.

In another study, glulisine demonstrated the same association, dissociation- and insulin-receptor affinity kinetics as RHI. ${ }^{21}$

\section{Other adverse effects}

When glulisine was compared with RHI in a small crossover trial in 10 adolescents and 10 children with type 1 diabetes, no safety concerns arose. ${ }^{1}$ Nineteen mild adverse events were reported in nine patients. Other than urticaria in a patient on RHI, details of the adverse reactions were not provided. There were no severe hypoglycemic events or clinically relevant abnormalities on physical examinations or in pathology tests.

When glulisine was compared with aspart in 59 adults with type 1 diabetes on CSII, unexplained hyperglycemia occurred in fewer patients in the glulisine group (20\% vs $40 \%){ }^{26}$

\section{Lipodystrophy and weight gain}

Lipodystrophy and weight gain can each occur in adult subjects on long-term glulisine therapy. ${ }^{32}$ However, the pediatric trials do not report data relating to these effects.

\section{Catheter occlusion in CSII pumps}

Although there are theoretical concerns that glulisine could be associated with an increase in catheter occlusion in CSII, ${ }^{16,27}$ the one study comparing glulisine with aspart in pumps did not show a significant difference in catheter occlusion, and rates for both were low. ${ }^{26}$

\section{Tolerability Flexibility of administration}

In general, use of rapid-acting insulin analogs gives greater flexibility for the timing of injections, especially important 
for children and teenagers. Insulin administration can be given immediately prior to or immediately after a meal, with the dose being adjusted according to carbohydrate intake, blood glucose level, and physical activity. The potential to give glulisine immediately after a meal, once food intake is known, can be invaluable in young children in whom carbohydrate and other food intake can vary widely and be difficult to predict. ${ }^{34}$ A comparable degree of glycemic control has been shown if glulisine is administered immediately prior to or 15 minutes after a meal. ${ }^{35}$

\section{Patient satisfaction}

There are no data relating to treatment satisfaction in patients on glulisine versus RHI. However, a number of studies, mainly in adults, have shown higher satisfaction in subjects on lispro or aspart compared with RHI. ${ }^{36,37}$ Adults randomized to aspart instead of RHI in an open label trial reported increased satisfaction, mainly due to increased meal and leisure time flexibility. ${ }^{38}$ As the pharmacodynamics and efficacy of glulisine are very similar to those of these other rapid-acting insulin analogs, it is likely that treatment satisfaction on glulisine will also be higher than for patients on RHI.

\section{Quality of life}

No specific studies have addressed quality of life (QoL) in patients on glulisine.

However, QoL was higher in children, adolescents, and adults transferred from RHI to lispro. ${ }^{38-41}$ and was also improved in the majority of Japanese children (78\%) with type 1 diabetes treated with rapid-acting insulin analogs, either aspart or lispro, compared with RHI. ${ }^{42}$ Since aspart, lispro, and glulisine have similar pharmacodynamics, it is likely that glulisine will also have a beneficial effect on QoL.

\section{Discussion}

Several large trials have studied glulisine in adult patients with type 1 and type 2 diabetes, but data in the pediatric population are limited. Glulisine compares favorably with other rapid-acting insulin analogs in the treatment of children with type 1 diabetes, but there is no evidence that it has superior safety or efficacy. However, it has been shown to be noninferior to lispro in terms of efficacy and safety as part of a basal-bolus regimen in pediatric patients with type 1 diabetes. ${ }^{25}$ It is thus a safe and effective short-acting insulin option in this population.
The pharmacokinetic and pharmacodynamic properties of glulisine appear to be similar in pediatric and adult patients. Glulisine has a similar kinetic profile to lispro and has a more rapid onset and shorter duration of action than RHI. ${ }^{22}$ These properties of rapid-acting insulin analogs are particularly advantageous in children, as they allow insulin administration postprandially or a short time preprandially with similar glycemic control. This is useful in young children, in whom it may be difficult to accurately predict carbohydrate intake. ${ }^{34}$ The shorter duration of action allows more flexibility of insulin dosing with variable activity levels.

There are no documented safety concerns with insulin glulisine use in children in a subcutaneous basal-bolus regimen. Rates of hypoglyemia are similar to rates with other rapid-acting analogs. Insulin injection-site reactions and systemic reactions are low and similar to those of other rapid-acting insulin analogs. In vitro studies do not suggest any increase in the risk of mitogenesis with glulisine.

There are still insufficient data to recommend routine use of glulisine in CSII in children, particularly in view of the possible concerns about catheter occlusion and insulin injection-site reactions. Despite this, while there are no published studies assessing the safety of glulisine administered via CSII in this population, a study comparing glulisine with aspart via CSII in adults revealed no adverse reactions. ${ }^{26}$

From the few published studies relating to glulisine in the pediatric population, it appears to provide a safe and effective option as a rapid-acting insulin analog as part of a basal-bolus regimen in children $\geq 4$ years of age with type 1 diabetes. ${ }^{7,8,32}$ Its use will be based on a combination of factors including clinician-patient preference, ease of administration (such as the use of the disposable SoloSTAR pen; sanofiaventis), and convenience with immediately pre- or postmeal injections. Comparative studies with the other rapid-acting insulin analogs are needed before the place of glulisine in the management of children and adolescents with type 1 diabetes can be better defined.

\section{Disclosure}

Dr Carter has received travel funds and/or Advisory Board payments from sanofi-aventis, NovoNordisk, and Eli Lilly. The other authors report no conflicts of interest in this work. 


\section{References}

1. DanneT, Lange K, Kordonouri O. New developments in the treatment of type 1 diabetes in children. Arch Dis Child. 2007;92(11):1015-1019.

2. The effect of intensive diabetes treatment on the development and progression of long-term complications in adolescents with insulindependent diabetes mellitus: The Diabetes Control and Complications Trial. Diabetes Control and Complications Trial Research Group. J Pediatr. 1994;125(2):177-188.

3. White NH, Cleary PA, Dahms W, Goldstein D, Malone J, Tamborlane WV. Diabetes Control and Complications Trial (DCCT)/ Epidemiology of Diabetes Interventions and Complications (EDIC) Research Group. Beneficial effects of intensive therapy of diabetes during adolescence outcomes after the conclusion of the Diabetes Control and Complications Trial. J Pediatr. 2001;139(6):804-812.

4. Dahl-Jorgensen KLJ, Hanssen KF. Atherosclerosis in childhood and adolescents type 1 diabetes: early disease, early treatment? Diabetologia. 2005;48(8):1445-1453.

5. Siebenhofer A, Plank J, Berghold A, et al. Short acting inuslin analogs versus regular human insulin in pateints with daibetes mellitus. Cochrane Database Syst Rev. 2004;2:CD003287.

6. Holcombe JH, Zalani S, Arora VK, Mast CJ. Comparison of insulin lispro with regular human insulin for the treatment of type 1 in adolescents. Clin Ther. 2002;24(4):629-638.

7. sanofi-aventis. Insulin glulisine $\left(\right.$ Apidra $\left.^{\circledR}\right)$. EU summary of product characteristics. Availalble from: http://www.emea.europa.eu/humandocs/ PDFs/EPAR/apidra/H-557-PI-en.pdf. Accessed 2010 Nov 5.

8. sanofi-aventis. Insulin Glulisine (Apidra $\left.{ }^{\circledR}\right)$ US prescribing information. Available from: http://products.sanofi-aventis.us/apidra/apidra.pdf. Accessed 2010 Nov 5.

9. Dailey G, Rosenstock J, Moses R, et al. Insulin glulisine provides improved glycemic control in patients with type 2 diabetes. Diabetes Care. 2005;37(11):702-707.

10. Rayman G, Profozic V, Middle M. Insuline glulisine imparts effective glycaemic control in patients with type 2 diabetes. Diabetes Res Clin Pract. 2007;76(2):304-312.

11. Lankisch M, Ferlinz K, Leahy J, Scherbaum WA, et al. Introducing a simplified approach to insulin therapy in type 2 diabetes: a comparison of two single-dose regiments of insulin glulisine plus insulin glargine and oral antidiabetic drugs. Diabetes Obes Metab. 2008;10(12):1178-1185.

12. National Institutes of Health. Clinical Trials. Available from: http://www. clinicaltrials.gov/. Accessed 2010 Nov 5.

13. Apidra TM. Aventis Pharmaceuticals, Inc. Insulin glulisine (rDNA origin) injection. Available from: http://www.acessdata.fda.gov/drugsatfda_docs/ label/2008/021629s015 lbll.pdf. Accessed 2010 Nov 5.

14. sanofi-aventis. Apidra prescribing information. Available from: http://products.sanofi-aventis.us/apidra/apidra.pdf. Accessd 2009 Nov 5.

15. Heise T, Heinemann L. Rapid and long-acting insulin analogues as an aproach to improve insulin therapy: an evidence-based medicine assessment. Curr Pharm Dis. 2001;7(14):1303-1325.

16. Poulsen C, Langkjær L, Worsøe C. Precipitation of insulin aspart and insulin glulisine products used for continuous subcutaneous insulin infusion. Diabetes Technol Ther. 2007;7(1):142-150.

17. Sluzky VTJ, Klibanov AM, Langer R. Kinetics of insulin aggregation in aqueous solutions upon agitation in the presence of hydrophobic surfaces. Proc Natl Acad Sci U S A. 1991;88(21):9377-9381.

18. Brange J, editor. Galenics of Insulin: The Physico-chemical and Pharmaceutical Aspects of Insulin and Insulin Preparations. Berlin, Germany: Springer-Verlag; 1987.

19. Richards JP, Stickelmeyer M, Flora DB, Chance RE, Frank BH, DeFelippis MR. Self association properties of monomeric insulin analogs under formulation conditions. Pharm Res. 1998;15(9):1434-1441.

20. Zoete V, Meuwly M, Karplus M. Study of the insulin dimerization: binding free energy calculation and per-residue free energy decomposition. Proteins. 2005;61(1):79-93.
21. Hennige AM, Strack V, Metzinger E, Seipke G, Häring HU, Kellerer M. Effects of new insulin analogues HMR1964 (insulin glulisine) and HMR1423 on insulin receptors. Diabetologica. 2005;48(9): 1891-1897.

22. Danne T, Becker RH, Heise T, Bittner C, Frick AD, Rave K. Pharmacokinetics, prandial glucose control, and safety of insulin glulisine in children and adolescents with type 1 diabetes. Diabetes Care. 2005; 28(9):2100-2105.

23. Garnock-Jones KP, Plosker GL. Insulin glulisine: a review of its use in the management of diabetes mellitus. Drugs. 2009;69(8): 1035-1057.

24. Garg S, Kelly WC. Insulin glargine and glulisine SoloSTAR pens for the treatment of diabetes. Expert Rev Med Devices. 2008;5(2): 113-123.

25. Philotheou A, Arslenian S, Blatnicky L, Peterkova V, Souhami E, Danne T. Efficacy and safety of insulin glulisine versus insulin lispro as part of a basal bolus regimen in children and adolescents with type 1 diabetes. Diabetologica. 2008;51(Supp 1:32):Abstract 950.

26. Hoogma RP, Schumicki D. Safety of insulin glulisine when given by continuous subcutaneous infusion using an external pump in patients with type 1 diabetes. Horm Metab Res. 2006;38(6):429-433.

27. Cobry E, McFann K, Messer L, et al. Timing of meal insulin boluses to achieve optimal postprandial glycemic control in patients with type 1 diabetes. Diabetes Technol Ther. 2010;12(3):173-177.

28. Garg SK, Rosenstock J, Ways K. Optimized basal-bolus insulin regimens in type 1 diabetes: insulin glulisine versus regular human insulin in combination with basal insulin glargine. Endocr Pract. 2005;11(1):11-17. [Erratum in Endocr Pract. 2005;11(2):145].

29. Kawamori R, Kadowaki T, Ishii H, et al. Efficacy and safety of insulin glulisne in japanese patients with type 1 diabetes mellitus; using glargine as basal insulin [Abstract Number 2074-PO]. Diabetes. 2008; 57 Suppl 1:A573.

30. Dreyer M, Prager R, Robinson A, et al. Efficacy and safety of insulin glulisine in patients with type 1 diabetes. Horm Metab Res. 2005; 37(11):702-707.

31. Senstius J, Poulsen C, Hvass A. Comparison of in vitro stability for insulin aspart and insulin glulisine during simulated use in insulin pumps. Diabetes Technol Ther. 2007;9:517-521.

32. sanofi-aventis. Apidra prescibing information. Available from: http://products.sanofi-aventis.us/apidra/apidra.html. Accessed 2009 Nov 4.

33. Stammberger I, Seipke G, Bartels T. Insulin glulisine - a comprehensive preclinical evaluation. Int J Toxicol. 2006;25(1):25-33.

34. Powers SW, Byars KC, Mitchell MJ, Patton SR, Standiford DA, Dolan LM. Parent report of mealtime behavior and parenting stress in young children with type 1 diabetes and in healthy control subjects. Diabetes Care. 2002;25(2):313-318.

35. Rave K, Klein O, Frick AD, Becker RH. Advantage of premeal-injected insulin glulisine compared with regular human insulin in subjects with type 1 diabetes. Diabetes Care. 2006;29(8):1812-1817.

36. Kotsanos JG, Vignati L, Huster W, et al. Health-related quality-of-life results from multinational clinical trials of insulin lispro: Assessing benefits of a new diabetes therapy. Diabetes Care. 1997;20(6): 948-958.

37. Home PD, Lindholm A, Riis A. European Insulin Aspart Study Group. Insulin aspart vs. human insulin in the management of long-term blood glucose control in type 1 diabetes mellitus: a randomized controlled trial. Diabet Med. 2000;17(11):762-770.

38. Bott S, Tusek C, Heinemann L, Friberg HH, Heise T. The pharmacokinetic and pharmacodynamic properties of biphasic insulin aspart 70 (BIAsp 70) are significantly different from those of biphasic insulin Aspart 30 (BIAsp 30). Exp Clin Endocrinol Diabetes. 2005;113(9): 545-550.

39. Kamoi K, Miyakoshi M, Maruyama R. A quality-of-life assessment of intensive insulin therapy using insulin lispro switched from short-acting insulin and measured by an ITR-QOL questionnaire: a prospective comparison of multiple daily insulin injections and continuous subcutaneous insulin infusion. Diabetes Res Clin Pract. 2004;64(1): 19-25. 
40. Grey M, Boland E, Tamborlane WV. Use of lispro insulin and quality of life in adolescents on intensive therapy. Diabetes Educator. 1999;25(6): 934-941.

41. Deja GJ-CP, Muchacka-Bianga M, et al. Insulin lispro in treatment of children and adolescents with type 1 diabetes and its effect on quality of life. Diabetologia Polska. 2002;9(2):52-56.
42. Urakami T, Kawamaru T, Sugihara S, et al; Japanese Study Group of Insulin Therapy for Childhood and Adolescent Diabetes. A questionnaire survey on the use of quick-acting insulin analog in Japanese children and adolescents with type 1 diabetes. Pediatr Int. 2004;46(3):285-290.

\section{Publish your work in this journal}

Diabetes, Metabolic Syndrome and Obesity: Targets and Therapy is an international, peer-reviewed open-access journal committed to the rapid publication of the latest laboratory and clinical findings in the fields of diabetes, metabolic syndrome and obesity research. Original research, review, case reports, hypothesis formation, expert opinion and commentaries are all considered for publication. The manuscript management system is completely online and includes a very quick and fair peer-review system, which is all easy to use. Visit http://www.dovepress.com/testimonials.php to read real quotes from published authors.

Submit your manuscript here: http://www.dovepress.com/diabetes-metabolic-syndrome-and-obesity-targets-and-therapy-journal 